\title{
Trauma complications and in-hospital mortality: failure-to-rescue
}

Toshikazu Abe ${ }^{1,2^{*}}$, Akira Komori ${ }^{3}$, Atsushi Shiraishi ${ }^{4}$, Takehiro Sugiyama ${ }^{1,5,6}$, Hiroki Iriyama ${ }^{3}$, Takako Kainoh ${ }^{3}$ and Daizoh Saitoh $^{7}$

\begin{abstract}
Background: Reducing medical errors and minimizing complications have become the focus of quality improvement in medicine. Failure-to-rescue (FTR) is defined as death after a surgical complication, which is an institution-level surgical safety and quality metric that is an important variable affecting mortality rates in hospitals. This study aims to examine whether complication and FTR are different across low- and high-mortality hospitals for trauma care.

Methods: This was a retrospective cohort study performed at trauma care hospitals registered at Japan Trauma Data Bank (JTDB) from 2004 to 2017. Trauma patients aged $\geq 15$ years with injury severity score (ISS) of $\geq 3$ and those who survived for $>48 \mathrm{~h}$ after hospital admission were included. The hospitals in JTDB were categorized into three groups by standardized mortality rate. We compared trauma complications, FTR, and in-hospital mortality by a standardized mortality rate (divided by the institute-level quartile).

Results: Among 184,214 patients that were enrolled, the rate of any complication was $12.7 \%$. The overall mortality rate was $3.7 \%$, and the mortality rate among trauma patients without complications was only $2.8 \%$ (non-precedented deaths). However, the mortality rate among trauma patients with any complications was 10.2\% (FTR). Hospitals were categorized into high- (40 facilities with 44,773 patients), average- (72 facilities with 102,368 patients), and low- (39 facilities with 37,073 patients) mortality hospitals, using the hospital ranking of a standardized mortality rate. High-mortality hospitals showed lower ISS than low-mortality hospitals [10 (IQR, 9-18) vs. 11 (IQR, 9-20), $P<0.01]$. Patients in high-mortality hospitals showed more complications ( $14.2 \%$ vs. $11.2 \%, P<0.01)$, in-hospital mortality $(5.1 \%$ vs. $2.5 \%, P<0.01)$, FTR (13.6\% vs. $7.4 \%$, $P<0.01)$, and non-precedented deaths $(3.6 \%$ vs. $1.9 \%, P<0.01)$ than those in low-mortality hospitals.
\end{abstract}

Conclusions: Unlike reports of elective surgery, complication rates and FTR are associated with in-hospital mortality rates at the center level in trauma care.

Keywords: Injuries, Hospital mortality, Indicators, Quality

\section{Key points}

- In this retrospective cohort study, patients in lowperformance hospitals showed more complications, in-hospital mortality, FTR, and non-precedented deaths than those in high-performance hospitals, unlike reports of elective surgery.

- A lower risk of complications and better care of those with complications could play crucial roles in trauma care.

\footnotetext{
* Correspondence: abetoshi111@gmail.com

'Department of Health Services Research, Faculty of Medicine, University of Tsukuba, 1-1-1 Tennodai, Tsukuba, Ibaraki 305-8577, Japan

${ }^{2}$ Department of Emergency and Critical Care Medicine, Tsukuba Memorial Hospital, Tsukuba, Japan

Full list of author information is available at the end of the article
}

\section{Background}

Reducing medical errors and minimizing complications have become the focus of quality improvement in the medical field [1]. Failure-to-rescue (FTR) is

(c) The Author(s). 2020 Open Access This article is licensed under a Creative Commons Attribution 4.0 International License, which permits use, sharing, adaptation, distribution and reproduction in any medium or format, as long as you give appropriate credit to the original author(s) and the source, provide a link to the Creative Commons licence, and indicate if changes were made. The images or other third party material in this article are included in the article's Creative Commons licence, unless indicated otherwise in a credit line to the material. If material is not included in the article's Creative Commons licence and your intended use is not permitted by statutory regulation or exceeds the permitted use, you will need to obtain permission directly from the copyright holder. To view a copy of this licence, visit http://creativecommons.org/licenses/by/4.0/ The Creative Commons Public Domain Dedication waiver (http://creativecommons.org/publicdomain/zero/1.0/) applies to the data made available in this article, unless otherwise stated in a credit line to the data. 
Table 1 Complications of trauma patients according to the hospital ranking (hospital performance)

\begin{tabular}{|c|c|c|c|c|}
\hline & \multicolumn{3}{|c|}{ Hospital outlier status } & \multirow{2}{*}{$\begin{array}{l}P \\
\text { value }\end{array}$} \\
\hline & Low-mortality & Average-mortality & High-mortality & \\
\hline Number of institutions & 39 & 72 & 40 & \\
\hline Number of patients & 37,073 & 102,368 & 44,773 & \\
\hline \multicolumn{5}{|l|}{ CNS } \\
\hline Diabetes insipidus & $89(0.2)$ & $226(0.2)$ & $139(0.31)$ & $<0.01$ \\
\hline Hydrencephalus & $53(0.1)$ & $261(0.3)$ & $104(0.2)$ & $<0.01$ \\
\hline Fat embolism & $22(0.1)$ & $189(0.2)$ & $32(0.1)$ & $<0.01$ \\
\hline Cerebrospinal fluid leakage & $115(0.3)$ & $178(1.2)$ & $98(0.2)$ & $<0.01$ \\
\hline Meningitis & $56(0.2)$ & $213(0.2)$ & $54(0.1)$ & $<0.01$ \\
\hline Higher brain dysfunction & $765(2.1)$ & $2006(2.0)$ & $940(2.1)$ & 0.16 \\
\hline Mental disorders (PTSD et al.) & $129(0.4)$ & $544(0.5)$ & $167(0.4)$ & $<0.01$ \\
\hline Others & $315(0.9)$ & $1232(1.2)$ & $746(1.7)$ & $<0.01$ \\
\hline \multicolumn{5}{|l|}{ Circulation } \\
\hline Acute coronary syndrome & $10(0.03)$ & $78(0.1)$ & $35(0.1)$ & $<0.01$ \\
\hline Lethal arrhythmia & $36(0.1)$ & $175(0.2)$ & $75(0.2)$ & $<0.01$ \\
\hline Acute kidney injury & $86(0.2)$ & $286(0.3)$ & $160(0.4)$ & $<0.01$ \\
\hline Abdominal compartment syndrome & $12(0.03)$ & $63(0.1)$ & $28(0.1)$ & 0.10 \\
\hline Others & $251(0.7)$ & $580(0.6)$ & $327(0.7)$ & $<0.01$ \\
\hline \multicolumn{5}{|l|}{ Respiratory } \\
\hline Lung edema & $40(0.1)$ & $182(0.2)$ & $99(0.2)$ & $<0.01$ \\
\hline Atelectasis & $466(1.3)$ & $1064(1.0)$ & $583(1.3)$ & $<0.01$ \\
\hline Pneumonia & $990(2.7)$ & $3286(3.2)$ & $1572(3.5)$ & $<0.01$ \\
\hline Pulmonary embolism & $88(0.2)$ & $640(0.6)$ & $72(0.2)$ & $<0.01$ \\
\hline Pyothorax & $26(0.1)$ & $74(0.1)$ & $45(0.1)$ & 0.17 \\
\hline ARDS and respiratory failure & $166(0.5)$ & $620(0.6)$ & $268(0.6)$ & $<0.01$ \\
\hline Others & $137(0.4)$ & $354(0.4)$ & $206(0.5)$ & $<0.01$ \\
\hline \multicolumn{5}{|l|}{ Gastroenterology and hepato-biliary } \\
\hline Ulcer and upper Gl bleeding & $87(0.2)$ & $573(0.6)$ & $157(0.4)$ & $<0.01$ \\
\hline lleus & $71(0.2)$ & $220(0.2)$ & $105(0.2)$ & 0.42 \\
\hline Pancreatitis & $25(0.1)$ & $68(0.1)$ & $35(0.1)$ & 0.72 \\
\hline Cholecystitis & $49(0.1)$ & $159(0.2)$ & $69(0.2)$ & 0.60 \\
\hline Hyperbilirubinemia and liver failure & $48(0.1)$ & $175(0.2)$ & $79(0.2)$ & 0.18 \\
\hline Others & $209(0.6)$ & $559(0.6)$ & $225(0.5)$ & 0.44 \\
\hline \multicolumn{5}{|l|}{ Bone and joint } \\
\hline Compartment syndrome & $63(0.2)$ & $411(0.4)$ & $126(0.3)$ & $<0.01$ \\
\hline Osteomyelitis & $23(0.1)$ & $450(0.4)$ & $34(0.1)$ & $<0.01$ \\
\hline Refracture & $17(0.1)$ & $376(0.4)$ & $14(0.03)$ & $<0.01$ \\
\hline Pseudoarthrosis & $23(0.1)$ & $393(0.4)$ & $24(0.1)$ & $<0.01$ \\
\hline Others & $75(0.2)$ & $336(0.3)$ & $160(0.4)$ & $<0.01$ \\
\hline \multicolumn{5}{|l|}{ Coagulation } \\
\hline DIC and coagulation disorder & $248(0.7)$ & $934(0.9)$ & $538(1.2)$ & $<0.01$ \\
\hline Thrombopenia $(<50,000)$ & $93(0.3)$ & $383(0.4)$ & $284(0.6)$ & $<0.01$ \\
\hline Others & $51(0.1)$ & $176(0.2)$ & $261(0.6)$ & $<0.01$ \\
\hline
\end{tabular}

Infection et al. 
Table 1 Complications of trauma patients according to the hospital ranking (hospital performance) (Continued)

\begin{tabular}{|c|c|c|c|c|}
\hline & \multicolumn{3}{|c|}{ Hospital outlier status } & \multirow{2}{*}{$\begin{array}{l}P \\
\text { value }\end{array}$} \\
\hline & Low-mortality & Average-mortality & High-mortality & \\
\hline Bacteremia & $120(0.3)$ & $379(0.4)$ & $192(0.4)$ & 0.05 \\
\hline Sepsis or MOF & $152(0.4)$ & $745(0.7)$ & $332(0.7)$ & $<0.01$ \\
\hline Abdominal abscess & $35(0.1)$ & $115(0.1)$ & $37(0.1)$ & 0.23 \\
\hline UTI & $582(1.6)$ & $1532(1.5)$ & $601(1.3)$ & 0.02 \\
\hline Infectious colitis & $26(0.1)$ & $101(0.1)$ & $62(0.1)$ & $<0.01$ \\
\hline Wound infection & $333(0.9)$ & $1528(1.5)$ & $464(1.0)$ & $<0.01$ \\
\hline Wound disruption & $89(0.2)$ & $323(0.3)$ & $102(0.2)$ & $<0.01$ \\
\hline Decubitus & $158(0.4)$ & $411(0.4)$ & $282(0.6)$ & $<0.01$ \\
\hline Hypothermia $\left(<35^{\circ} \mathrm{C}\right)$ & $49(0.1)$ & $173(0.2)$ & $203(0.5)$ & $<0.01$ \\
\hline Drug allergy & $41(0.1)$ & $117(0.1)$ & $51(0.1)$ & 0.98 \\
\hline Others & $232(0.6)$ & $972(1.0)$ & $442(1.0)$ & $<0.01$ \\
\hline Any complications & $4164 / 37,073(11.2)$ & $12,838 / 102,368(12.5)$ & $6346 / 44,773(14.2)$ & $<0.01$ \\
\hline
\end{tabular}

PTSD post-traumatic stress disorder, ARDS acute respiratory distress syndrome, GI gastrointestinal, DIC disseminated intravascular coagulation, MOF multiple organ failure, UTI urinary tract infection

defined as death after a surgical complication [2]. Regarding elective surgery, a study showed that at the hospital level, complications and mortality were not correlated, but FTR and mortality were correlated [3]. Therefore, the focus should not be on improvising operative techniques to prevent complications but on more efficient rescuing from the complications. Thus, FTR is an institution-level surgical safety and quality metric [4] and is considered an important variable affecting mortality rates in hospitals [5]; this metric indicates the ability of a hospital to identify and successfully manage complications [6].

Recently also in a case of trauma, FTR was found to be an important variable [7] because it is more about an institution's ability to rescue those who develop complications [8-10]. Nevertheless, whether FTR in trauma

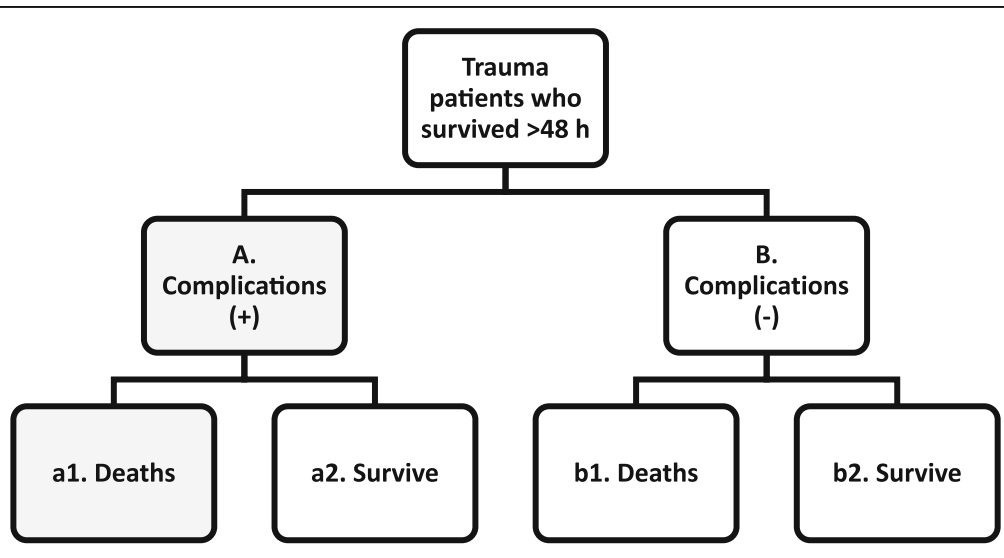

Failure to Rescue $($ FTR $)=a 1 / A$

Non-precedented deaths $=\mathrm{b} 1 / \mathrm{B}$

Fig. 1 Conceptualization of the study. Among trauma patients who survived for $>48 \mathrm{~h}$, some patients suffered from complications, while others did not; the proportion of patients with complications is the "complication rate," which is one of the outcome indicators. Those who suffered from complications were more likely to die than those who did not suffer from complications, i.e., the rate of "failure-to-rescue (FTR)," which is another outcome indicator, is naturally more than the rate of "non-precedented deaths." Overall in-hospital mortality comprises these components. However, unlike reports of elective surgery, it has been controversial whether complication rate or FTR explains more variations in in-hospital mortality. In addition, FTR in trauma complication studies includes not only patients who have undergone surgery but also those who have not undergone surgery; this is inconsistent with studies on elective surgery. We investigated this research question in the present study 


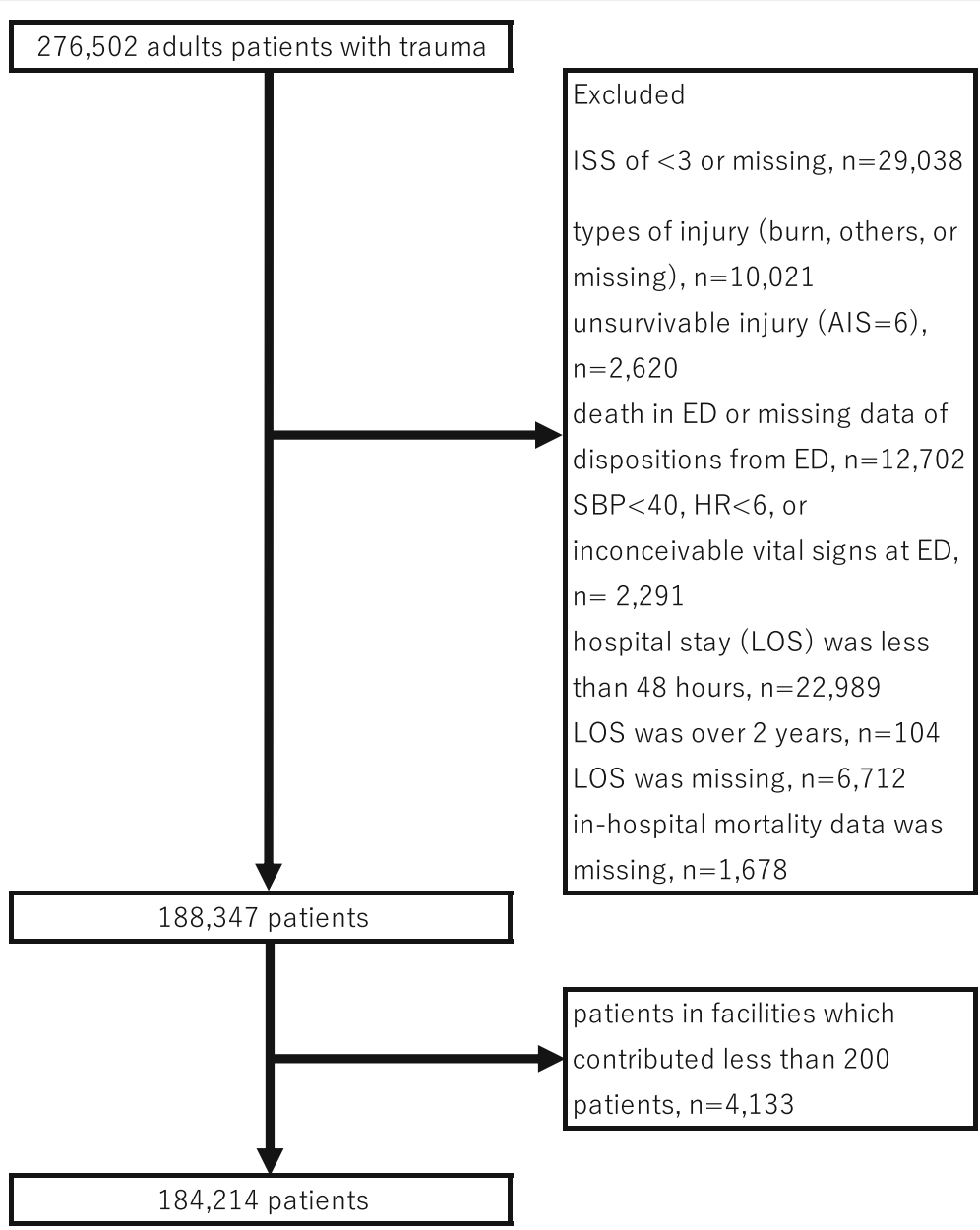

Fig. 2 Participant selection

care contributes to variations in mortality across centers [7] remains debatable, as there are some concerns regarding the use of FTR as a quality measure of trauma care [11]. First, severe trauma patients die in the hours immediately after injury, although all patients after elective surgery ideally survive. Outcomes after trauma complications may be less modifiable. FTR might play a relatively minor role in trauma patients compared with those after elective surgery. Moreover, with rapid progress in endovascular interventions and intensive care, surgeries for trauma have reduced. Conceivably, complications and FTR should be important in trauma patients regardless of FTR playing a minor or major role. Therefore, our aim was to investigate the association between a complication rate and FTR and a hospital performance level of trauma care in hospitals.

\section{Methods}

\section{Design and setting}

This was a retrospective cohort study using the Japan Trauma Data Bank (JTDB), which is a nationwide trauma registry established in 2003 by the Japanese Association for the Surgery of Trauma and by the Japanese Association for Acute Medicine with the aim of improving and ensuring the quality of trauma care in Japan, and compiled by the JTDB investigators [12]. A total of 264 hospitals, including $95 \%$ of the tertiary emergency medical centers in Japan, participated in the JTDB in 2017.

\section{Participants}

Patients aged $\geq 15$ years with an injury severity score (ISS) of $\geq 3$ and diagnosed with trauma between 2004 and 2017 were enrolled in this study. Only patients who survived for $>48 \mathrm{~h}$ after hospital admission were included to exclude the impact of early deaths. Patients with pre-hospital or emergency department (ED) death, un-survivable [abbreviated injury scale (AIS) score of 6], burns, or unknown trauma mechanisms, missing data of inhospital death, and hospital for $>2$ years were excluded. Similar to a previous report [7], the current 
Table 2 Demographics and characteristics of trauma patients according to the hospital ranking (hospital performance)

\begin{tabular}{|c|c|c|c|c|}
\hline & \multicolumn{3}{|c|}{ Hospital outlier status } & \multirow[b]{2}{*}{$P$ value } \\
\hline & Low-mortality & Average-mortality & High-mortality & \\
\hline Number of institutions & 39 & 72 & 40 & \\
\hline Number of patients & 37,073 & 102,368 & 44,773 & \\
\hline Age & $65(45-80)$ & $65(44-79)$ & $64(42-79)$ & $<0.01$ \\
\hline Sex (male) & $22,343(60.3)$ & $61,702(60.3)$ & $27,038(60.4)$ & 0.90 \\
\hline \multicolumn{5}{|l|}{ Type of injury } \\
\hline Blunt (vs. penetrate) & $35,983(97.1)$ & $99,391(97.1)$ & $43,340(96.8)$ & $<0.01$ \\
\hline \multicolumn{5}{|l|}{$\operatorname{AIS}(\geq 3)$} \\
\hline Head & $10,570(28.5)$ & $31,627(30.9)$ & $13,956(31.2)$ & $<0.01$ \\
\hline Face & $389(1.1)$ & $758(0.7)$ & $250(0.6)$ & $<0.01$ \\
\hline Neck & $178(0.5)$ & $398(0.4)$ & $149(0.3)$ & $<0.01$ \\
\hline Thorax & $8268(22.3)$ & $22,635(22.1)$ & $9619(21.5)$ & $<0.01$ \\
\hline Abdomen and pelvis & $2111(5.7)$ & $6067(5.9)$ & $2326(5.2)$ & $<0.01$ \\
\hline Spine & $4286(11.6)$ & $11,048(10.8)$ & $4228(9.4)$ & $<0.01$ \\
\hline Upper extremity & $2150(5.8)$ & $5917(5.8)$ & $1907(4.3)$ & $<0.01$ \\
\hline Lower extremity & $11,300(30.5)$ & $34,763(34.0)$ & $15,289(34.2)$ & $<0.01$ \\
\hline Body surface & $16(0.04)$ & $60(0.1)$ & $32(0.1)$ & 0.25 \\
\hline ISS & $11(9-20)$ & $11(9-19)$ & $10(9-18)$ & $<0.01$ \\
\hline \multicolumn{5}{|l|}{ Vital signs at arrival } \\
\hline GCS & $15(14-15)$ & $15(14-15)$ & $15(14-15)$ & $<0.01$ \\
\hline SBP & $137(118-157)$ & 138 (119-158) & 139 (119-160) & $<0.01$ \\
\hline $\mathrm{HR}$ & $82(71-95)$ & $82(72-95)$ & $83(72-96)$ & $<0.01$ \\
\hline $\mathrm{RR}$ & $20(17-24)$ & $20(17-24)$ & $20(18-24)$ & $<0.01$ \\
\hline BT & $36.5(36-37)$ & $36.5(36-37)$ & $36.5(36-37)$ & $<0.01$ \\
\hline Alcohol & $2803(12.0)$ & $9386(14.2)$ & $4638(15.0)$ & $<0.01$ \\
\hline \multicolumn{5}{|l|}{ Comorbidities } \\
\hline Ischemic heart diseases & $1620(4.4)$ & $4281(4.2)$ & $1702(3.8)$ & $<0.01$ \\
\hline Heart failure & $1180(3.2)$ & $2322(2.3)$ & $966(2.2)$ & $<0.01$ \\
\hline Hypertension & $9970(26.9)$ & $26,083(25.5)$ & $10,983(24.5)$ & $<0.01$ \\
\hline Other cardiac diseases & $1582(4.3)$ & $4995(4.9)$ & $2143(4.8)$ & $<0.01$ \\
\hline Asthma & $1044(2.8)$ & $3152(3.1)$ & $1388(3.1)$ & $<0.01$ \\
\hline COPD & $243(0.7)$ & $746(0.7)$ & $310(0.7)$ & 0.329 \\
\hline Other chronic lung diseases & $448(1.2)$ & $1018(1.0)$ & $505(1.1)$ & $<0.01$ \\
\hline Liver cirrhosis & $267(0.7)$ & $728(0.7)$ & $366(0.8)$ & 0.08 \\
\hline Chronic hepatitis & $596(1.6)$ & $1376(1.3)$ & $645(1.4)$ & $<0.01$ \\
\hline Peptic ulcer & $530(1.4)$ & $2357(2.3)$ & $911(2.0)$ & $<0.01$ \\
\hline Inflammatory bowel diseases & $253(0.7)$ & $676(0.7)$ & $170(0.4)$ & $<0.01$ \\
\hline Other gastrointestinal diseases & $1568(4.2)$ & $3878(3.8)$ & $1637(3.7)$ & $<0.01$ \\
\hline DM & $4152(11.2)$ & $11,207(11.0)$ & $4856(10.9)$ & 0.25 \\
\hline Obesity & $47(0.1)$ & $108(0.1)$ & $71(0.2)$ & 0.03 \\
\hline Other metabolic diseases & $1113(3.0)$ & $3342(3.3)$ & $1372(3.1)$ & 0.02 \\
\hline Stroke & $2260(6.1)$ & $6243(6.1)$ & $2291(5.1)$ & $<0.01$ \\
\hline Psychiatric disease & $1888(5.1)$ & $5600(5.5)$ & $3039(6.8)$ & $<0.01$ \\
\hline Dementia & $2550(6.9)$ & $6771(6.6)$ & $2867(6.4)$ & 0.03 \\
\hline
\end{tabular}


Table 2 Demographics and characteristics of trauma patients according to the hospital ranking (hospital performance) (Continued)

\begin{tabular}{|c|c|c|c|c|}
\hline & \multicolumn{3}{|c|}{ Hospital outlier status } & \multirow[b]{2}{*}{$P$ value } \\
\hline & Low-mortality & Average-mortality & High-mortality & \\
\hline Other neurological diseases & $834(2.3)$ & $2922(2.9)$ & $1287(2.9)$ & $<0.01$ \\
\hline HIV & $8(0.02)$ & $22(0.02)$ & $6(0.01)$ & 0.57 \\
\hline Malignancies & $875(2.4)$ & $2770(2.7)$ & $877(2.0)$ & $<0.01$ \\
\hline Hematological diseases & $89(0.2)$ & $350(0.3)$ & $121(0.3)$ & $<0.01$ \\
\hline Chronic renal failure or $\mathrm{HD}$ & $516(1.4)$ & $2452(2.4)$ & $507(1.1)$ & $<0.01$ \\
\hline Pregnancy & $14(0.04)$ & $41(0.04)$ & $20(0.04)$ & 0.88 \\
\hline Others & $1384(3.7)$ & $4750(4.6)$ & $2404(5.4)$ & $<0.01$ \\
\hline Steroid use & $650(1.8)$ & $1629(1.6)$ & $658(1.5)$ & $<0.01$ \\
\hline Immunosuppressant use & $170(0.5)$ & $358(0.4)$ & $119(0.3)$ & $<0.01$ \\
\hline Anticoagulant use & $73(0.2)$ & $135(0.1)$ & $36(01)$ & $<0.01$ \\
\hline Previous healthy (no comorbidities reported) & $16,893(45.6)$ & $45,356(44.3)$ & 20,037 (44.8) & $<0.01$ \\
\hline
\end{tabular}

Missing data: gender $=45, \mathrm{GCS}=14,509, \mathrm{SBP}=2705, \mathrm{HR}=6523, \mathrm{RR}=25,223, \mathrm{BT}=19,734$, alcohol $=63,683$

$A I S$ abbreviated injury scale, ISS injury severity score, GCS Glasgow coma scale, SBP systolic blood pressure, $H R$ heart rate, $R R$ respiratory rate, $B T$ body temperature, COPD chronic obstructive pulmonary disease, DM diabetes mellitus, HIV human immunodeficiency virus; hemodialysis

analysis was limited to hospitals contributing at least 200 patients to the cohort during the entire study period.

\section{Data collection}

Data related to patient and hospital information in the JTDB include patient demographics, AIS, ISS, prehospital and in-hospital procedures, and clinical outcomes. Data collection was performed as part of the routine clinical patient management.

\section{Data definitions}

The definition of complication was in accordance with the JTDB (Table 1), wherein FTR was defined as in-hospital mortality after at least one trauma complication. Non-precedented death was defined as patient death without any complications. Many trauma patients did not undergo surgical interventions, but FTR was considered in this study regardless of whether they underwent surgery, similar to a previous study [13]. Figure 1 shows the conceptualization of the study. The hospitals were separated into three groups by standardized mortality rate (hospital ranking).

\section{Analysis}

To investigate the association between a hospital ranking (hospital performance level of trauma care) and trauma complications, FTR, and in-hospital mortality, the hospitals were ranked low, average, or high by standardized mortality rates. First, we performed a logistic regression model to predict the probability of deaths $\left[\mathrm{P}_{\mathrm{p}}(\mathrm{E})\right]$ after adjusting for baseline patient and trauma characteristics, which included patient's age, sex, mechanism of injury, ISS, and vital signs at ED (Glasgow Coma Scale, systolic blood pressure, and heart rate). These variables were chosen based on clinical relevance and a previous study [7]. Next, the predicted probability of death for each patient at each hospital was summed to obtain a predicted mortality rate for each hospital $\left[\mathrm{P}_{\mathrm{c}}(\mathrm{E})\right]$. In addition, we also calculated an observed in-hospital mortality rate $\left[\mathrm{P}_{\mathrm{c}}(\mathrm{O})\right]$ at each hospital. To yield a standardized mortality rate at each hospital, the overall mortality rate was multiplied by observed to expected $\left[\mathrm{P}_{\mathrm{c}}(\mathrm{O}) / \mathrm{P}_{\mathrm{c}}(\mathrm{E})\right]$ mortality ratio. Finally, hospitals were divided into three by the quartile of standardized mortality rate.

We compared the baseline characteristics, treatments, complications, and outcomes by the hospital ranking. Categorical variables were expressed as counts and percentages with comparisons performed using the chi-square test. Continuous variables were expressed as medians and interquartile ranges (IQRs) using the Kruskal-Wallis test because our study variables were not normally distributed.

We calculated the correlation coefficient between complication rate and FTR and in-hospital mortality and showed the correlation using bubble plots in all hospitals. As a sensitivity analysis, this correlation was analyzed based on the data from hospitals contributing at least 20 patients with complications in the cohort to avoid reporting bias.

All $P$ values were two-sided, and $P<0.05$ was considered statistically significant. We performed statistical analyses using the Stata software, version 15.1 (StataCorp, TX, USA). Bubble plots were drawn using JMP version 14.0 (SAS Institute, Cary, NC). 
Table 3 Treatments and interventions of trauma patients according to the hospital ranking (hospital performance)

\begin{tabular}{|c|c|c|c|c|}
\hline & \multicolumn{3}{|c|}{ Hospital outlier status } & \multirow[b]{2}{*}{$P$ valu } \\
\hline & Low-mortality & Average-mortality & High-mortality & \\
\hline Number of institutions & 39 & 72 & 40 & \\
\hline Number of patients & 37,073 & 102,368 & 44,773 & \\
\hline Blood transfusion within $24 \mathrm{~h}$ & $5613(15.4)$ & $13,472(13.5)$ & $6276(14.3)$ & $<0.01$ \\
\hline \multicolumn{5}{|l|}{ Emergency procedures } \\
\hline Oral intubation & $2982(8.0)$ & $9246(9.0)$ & $5589(12.5)$ & $<0.01$ \\
\hline Nasal intubation & $42(0.1)$ & $184(0.2)$ & $114(0.3)$ & $<0.01$ \\
\hline Cricothyroidotomy & $44(0.1)$ & $114(0.1)$ & $60(0.1)$ & 0.51 \\
\hline Ventilator use & $2925(7.9)$ & $6904(6.7)$ & $4562(10.2)$ & $<0.01$ \\
\hline Closed CPR & $44(0.1)$ & $165(0.2)$ & $80(0.2)$ & 0.09 \\
\hline Open CPR & $14(0.04)$ & $55(0.1)$ & $5(0.01)$ & $<0.01$ \\
\hline Aortic cross clamping & $14(0.04)$ & $46(0.04)$ & $14(0.03)$ & 0.47 \\
\hline REBOA & $73(0.2)$ & $295(0.3)$ & $137(0.3)$ & $<0.01$ \\
\hline Thoracentesis & $63(0.2)$ & $181(0.2)$ & $128(0.3)$ & $<0.01$ \\
\hline Chest drainage & $2012(5.4)$ & $6187(6.0)$ & $2867(6.4)$ & $<0.01$ \\
\hline Pericardial puncture & $18(0.1)$ & $47(0.1)$ & $24(0.1)$ & 0.83 \\
\hline Pericardial fenestration & $12(0.03)$ & $32(0.03)$ & $12(0.03)$ & 0.88 \\
\hline Shock pants use & $8(0.02)$ & $20(0.02)$ & $5(0.01)$ & 0.46 \\
\hline Tourniquet use & $40(0.1)$ & $171(0.17)$ & $99(0.22)$ & $<0.01$ \\
\hline Emergency craterization & $240(0.7)$ & $678(0.7)$ & $372(0.8)$ & $<0.01$ \\
\hline Emergency TAE & $868(2.3)$ & $3407(3.3)$ & $1270(2.8)$ & $<0.01$ \\
\hline Central venous line use & $1247(3.4)$ & $3235(3.2)$ & $2141(4.8)$ & $<0.01$ \\
\hline Blood transfusion within $24 \mathrm{~h}$ & $2754(7.4)$ & $8176(8.0)$ & $3608(8.1)$ & $<0.01$ \\
\hline Vasopressor use & $454(1.2)$ & $1321(1.3)$ & $819(1.8)$ & $<0.01$ \\
\hline Open spine traction & $76(0.2)$ & $177(0.2)$ & $117(0.3)$ & $<0.01$ \\
\hline Open bone traction & $1834(5.0)$ & $5571(5.4)$ & $4650(10.4)$ & $<0.01$ \\
\hline External skeletal fixation & $864(2.3)$ & $3043(3.0)$ & $1390(3.1)$ & $<0.01$ \\
\hline Other emergency bone fixation & $1911(5.2)$ & $4389(4.3)$ & $1625(3.6)$ & $<0.01$ \\
\hline \multicolumn{5}{|l|}{ Primary surgeries } \\
\hline Craniotomy & $1410(3.8)$ & $3785(3.7)$ & $1751(3.9)$ & 0.14 \\
\hline Craterization & $708(1.9)$ & $1505(1.5)$ & $610(1.4)$ & $<0.01$ \\
\hline Thoracotomy & $211(0.6)$ & $655(0.6)$ & $289(0.7)$ & 0.281 \\
\hline Celiotomy & $1156(3.1)$ & $2920(2.9)$ & $1229(2.8)$ & $<0.01$ \\
\hline Bone reduction and fixation & $14,059(37.9)$ & $36,124(35.3)$ & $15,418(34.5)$ & $<0.01$ \\
\hline Revascularization & $203(0.6)$ & $471(0.5)$ & $215(0.5)$ & 0.12 \\
\hline TAE & $1169(3.2)$ & $3170(3.1)$ & $1423(3.2)$ & 0.69 \\
\hline Endoscopic surgery & $85(0.2)$ & $157(0.2)$ & $78(0.2)$ & 0.01 \\
\hline Replantation of limbs and digits & $131(0.4)$ & $298(0.3)$ & $183(0.4)$ & $<0.01$ \\
\hline Hemostasis & $598(1.6)$ & $1221(1.2)$ & $609(1.4)$ & $<0.01$ \\
\hline Others & $1925(5.2)$ & $3973(3.9)$ & $2073(4.6)$ & $<0.01$ \\
\hline \multicolumn{5}{|l|}{ Secondary surgeries } \\
\hline Craniotomy & $225(0.6)$ & $490(0.5)$ & $205(0.5)$ & $<0.01$ \\
\hline Craterization & $55(0.2)$ & $119(0.1)$ & $41(0.1)$ & 0.06 \\
\hline Thoracotomy & $40(0.1)$ & $79(0.1)$ & $25(0.1)$ & 0.03 \\
\hline
\end{tabular}


Table 3 Treatments and interventions of trauma patients according to the hospital ranking (hospital performance) (Continued)

\begin{tabular}{|c|c|c|c|c|}
\hline & \multicolumn{3}{|c|}{ Hospital outlier status } & \multirow[b]{2}{*}{$P$ value } \\
\hline & Low-mortality & Average-mortality & High-mortality & \\
\hline Celiotomy & $193(0.5)$ & $406(0.4)$ & $159(0.4)$ & $<0.01$ \\
\hline Bone reduction and fixation & $497(1.4)$ & $1142(1.1)$ & $431(1.0)$ & $<0.01$ \\
\hline Revascularization & $10(0.03)$ & $31(0.03)$ & $17(0.04)$ & 0.66 \\
\hline TAE & $104(0.3)$ & $219(0.22)$ & $87(0.2)$ & 0.02 \\
\hline Endoscopic surgery & $7(0.02)$ & $7(0.01)$ & $6(0.01)$ & 0.14 \\
\hline Hemostasis & $31(0.1)$ & $98(0.1)$ & $53(0.1)$ & 0.28 \\
\hline Any interventions & $23,770(64.1)$ & $62,326(60.9)$ & $28,083(62.7)$ & $<0.01$ \\
\hline Any emergency procedures & $9993(27.0)$ & $30,011(29.3)$ & $16,037(35.8)$ & $<0.01$ \\
\hline Any primary surgeries & $20,281(54.7)$ & $51,652(50.0)$ & $22,553(50.4)$ & $<0.01$ \\
\hline Any secondary surgeries & $1079(2.9)$ & $2420(2.4)$ & $952(2.1)$ & $<0.01$ \\
\hline
\end{tabular}

Emergency procedures: procedures performed during the emergency department stayed. Primary surgeries: surgeries performed at the first time. Any interventions = any primary surgeries or any secondary surgeries or any emergency procedures. Missing data: blood transfusion $=3891$, primary surgeries (craniotomy $=158$, craterization $=157$, thoracotomy $=159$, celiotomy $=159$, bone reduction and fixation $=150$, revascularization $=157$, TAE $=157$, endoscopic surgery $=159$, replantation of limbs and digits $=159$, hemostasis $=158$, others $=155$ ), secondary surgeries (craniotomy $=2011$, craterization $=2011$, thoracotomy $=$ 2011 , celiotomy $=2010$, bone reduction and fixation $=2009$, revascularization $=2011, T A E=2011$, endoscopic surgery $=2011$, hemostasis $=2011$ )

$C P R$ cardiopulmonary resuscitation, REBOA resuscitative endovascular balloon occlusion of the aorta, TAE transcatheter arterial embolization

\section{Results}

Of 294, 274 patients in the JTDB, there were 276, 502 adults ( $\geq 15$ years) with trauma. Among these, 188, 347 met the inclusion and exclusion criteria, and after excluding patients in hospitals that contributed less than 200 patients to the JTDB, 184, 214 patients were analyzed in this study (Fig. 2).
The prevalence of any complication was $12.7 \%$. The most frequent complications were pneumonia (3.2\%), higher brain dysfunction $(2.0 \%)$, urinary tract infection $(1.5 \%)$, and atelectasis $(1.2 \%)$. The overall mortality rate was $3.7 \%$, and the mortality rate among trauma patients without complications was only $2.8 \%$ (non-precedented deaths). However, the mortality rate among trauma patients with any complications was $10.2 \%$ (FTR).

Table 4 Outcomes of trauma patients according to the hospital ranking (hospital performance)

\begin{tabular}{|c|c|c|c|c|}
\hline & \multicolumn{3}{|c|}{ Hospital outlier status } & \multirow[b]{2}{*}{$P$ value } \\
\hline & Low-mortality & Average-mortality & High-mortality & \\
\hline Number of institutions & 39 & 72 & 40 & \\
\hline Number of patients & 37,073 & 102,368 & 44,773 & \\
\hline Expected mortality, mean \pm SD & $3.9 \pm 8.5$ & $3.7 \pm 8.1$ & $3.7 \pm 8.0$ & $<0.01$ \\
\hline In-hospital mortality, n/total (\%) & $942 / 37,073(2.5)$ & $3622 / 102,368(3.5)$ & $2264 / 44,773(5.1)$ & $<0.01$ \\
\hline \multicolumn{5}{|l|}{ Failure-to-rescue (FTR), n/total (\%) } \\
\hline$(n=23,348)$ & $309 / 4164(7.4)$ & $1198 / 12,838(9.3)$ & $864 / 6346(13.6)$ & $<0.01$ \\
\hline \multicolumn{5}{|l|}{ Non-precedented deaths, n/total (\%) } \\
\hline$(n=160,866)$ & $633 / 32,909(1.9)$ & $2424 / 89,530(2.7)$ & $1400 / 38,427(3.6)$ & $<0.01$ \\
\hline \multicolumn{5}{|l|}{ Admission, $n /$ total (\%) } \\
\hline $\mathrm{ICU}$ & $22,242(60.0)$ & $58,938(57.6)$ & $26,064(58.2)$ & $<0.01$ \\
\hline Ward & $14,750(39.8)$ & $41,347(40.4)$ & $18,173(40.6)$ & \\
\hline Others & $81(0.2)$ & $2083(2.0)$ & $536(1.2)$ & \\
\hline \multicolumn{5}{|l|}{ Place after discharge, $n /$ total (\%) } \\
\hline Home & $13,779(37.2)$ & $48,428(47.4)$ & $21,195(47.4)$ & $<0.01$ \\
\hline Another facility & $21,687(58.5)$ & $48,095(47.1)$ & $20,398(45.6)$ & \\
\hline Others & $650(1.8)$ & $2009(2.0)$ & $849(1.9)$ & \\
\hline Length of hospital stay, median (IQR), days & $18(10-31)$ & $21(10-37)$ & $22(11-39)$ & $<0.01$ \\
\hline
\end{tabular}

Missing: place after discharge $=269$. Data was individual level 


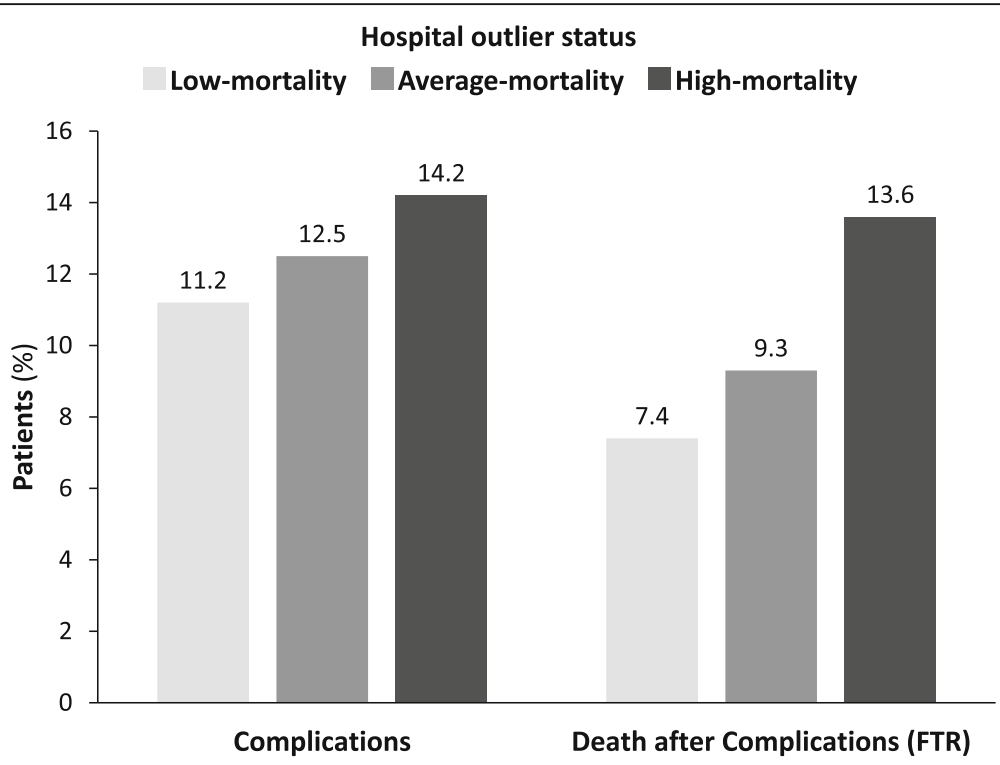

Fig. 3 Complication rates and death after complications (failure-to-rescue) according to the hospital ranking (hospital performance). Complication rates and death after complications (failure-to-rescue) varied across the hospital ranking. The rate of death in patients with complications was almost twice as high in in-hospital patients with high mortality as in those with low mortality $(7.4 \%$ vs. 13.6, $P<0.01)$

Hospitals were categorized into high- (40 facilities with 44,773 patients), average- (72 facilities with 102,368 patients), and low- (39 facilities with 37,073 patients) mortality hospitals, using the hospital ranking (hospital performance).

Demographics and characteristics of trauma patients according to the hospital ranking (hospital performance) are shown in Table 2. High-mortality hospitals showed lower ISS than low-mortality hospitals [10 (IQR, 9-18) vs. 11 (IQR, 9-20), $P<0.01$ ]. Treatments and interventions in trauma patients according to the hospital ranking (hospital performance) are shown in Table 3. Though patients in high-mortality hospitals received more emergency procedures in EDs than those in low-mortality hospitals $(35.8 \%$ vs. $27.0 \%$, $P<0.01)$, the former received fewer primary $(50.4 \%$ vs. $54.7 \%, P<0.01)$ and secondary surgeries $(2.1 \%$ vs. $2.9 \%, P<0.01)$ than the latter. Further, patients in high-mortality hospitals had more complications than those in low-mortality hospitals $(14.2 \%$ vs. $11.2 \%, P<0.01$, Table 1).

Individual complications did not show a consistent pattern across the hospital ranking (hospital performance). Clinically, pneumonia, disseminated intravascular coagulation, coagulation disorder, and thrombocytopenia occurred more often in highmortality hospitals than in low-mortality hospitals. An examination of outcomes according to the hospital ranking (hospital performance) (Table 4) revealed that high-mortality hospitals had significantly lower expected mortality than low-mortality hospitals did $(3.7 \pm 8.0 \%$ vs. $3.9 \pm 8.5 \%, P<0.01)$. However, inhospital mortality $(5.1 \%$ vs. $2.5 \%, P<0.01)$, FTR (13.6\% vs. $7.4 \%, P<0.01$ ), and non-precedented deaths (3.6\% vs. $1.9 \%, P<0.01)$ were higher in high-mortality hospitals than in low-mortality hospitals (Fig. 3).

The correlation coefficient $\left(r^{2}\right)$ between complication rate and in-hospital mortality was $0.2728(P<$ 0.01 ) for hospitals contributing at least 20 patients with complications to the cohort complications $(n=$ $128)$ and $0.2727(P<0.01)$ in all hospitals $(n=151)$. Figure 4 shows the correlation bubble plot. The correlation coefficient $\left(r^{2}\right)$ between FTR and inhospital mortality was $0.2766(P<0.01)$ for hospitals contributing at least 20 patients with complications to the cohort complications $(n=128)$ and 0.0716 $(P=0.39)$ in all hospitals $(n=148)$. Figure 5 shows the correlation bubble plot.

\section{Discussion}

Our study indicated that complication rates and FTR were associated to in-hospital mortality rates at the center level, as previously reported [7]. Better patient care in high-performing trauma hospitals could be related to a lower risk of complications and rescue from a complication.

In-hospital mortality among trauma patients with complications (FTR) was almost two times more in high-mortality hospitals compared to low-mortality hospitals, similar to a previous study [7]. Our findings are also in line with another study [1], which was higher in high-mortality hospitals compared with 


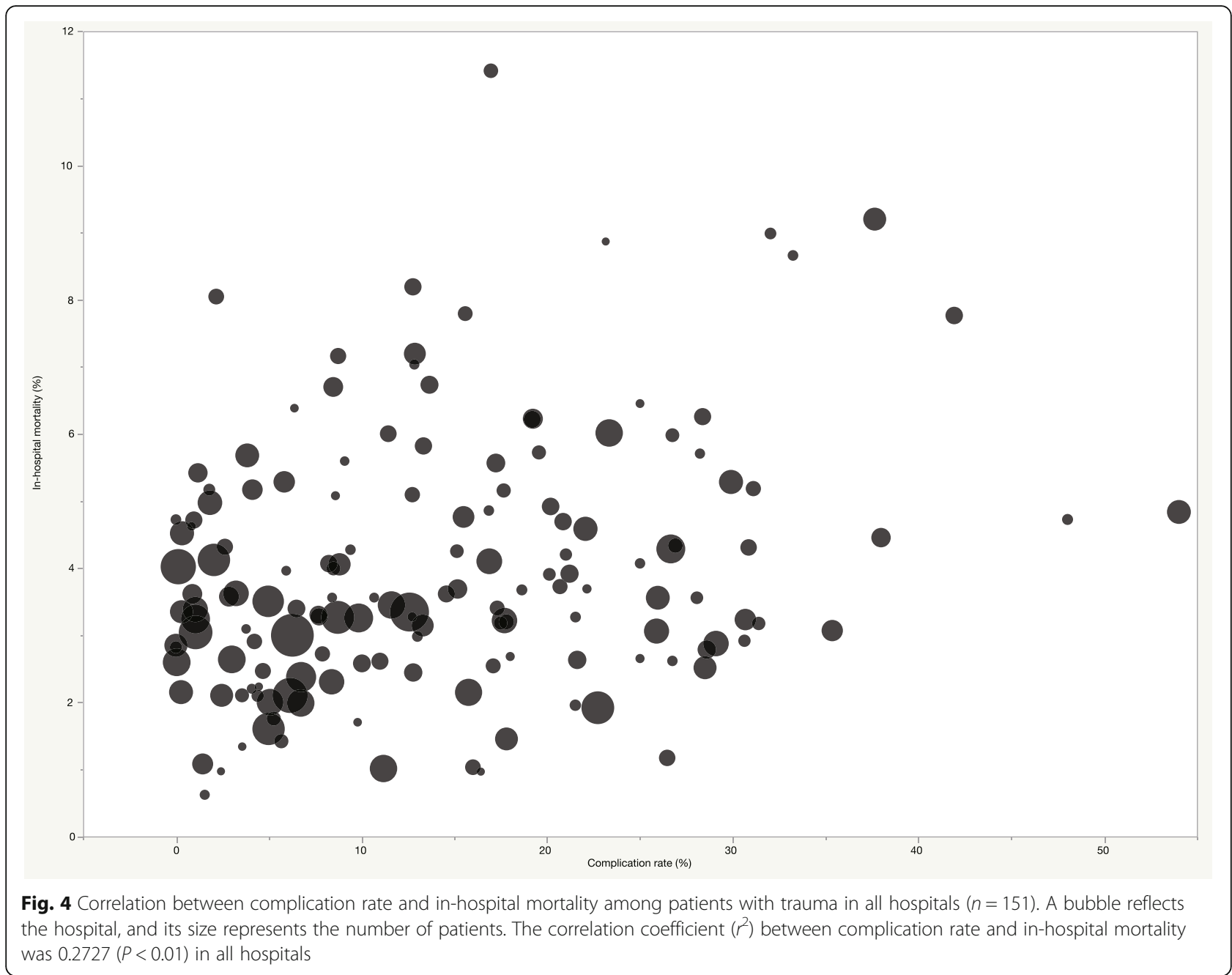

low-mortality hospitals. However, previous studies [1, 7] showed discordant results regarding the complication rates. A study showed both lower complication rate and lower FTR related to patient's better outcomes [7], but another study showed lower FTR related to patient's better outcomes despite the similarity in complication rates in each hospital [1]; this was consistent with a previous report on elective surgery [3]. Our study supported the former [7]. Successful rescue of patients with complications after trauma would have led to lower mortality rates in high-performance hospitals. To improve the quality of trauma care, it is important not only to survive the trauma but also to avoid complications, and to be rescued from complications as well. Therefore, FTR is a reasonable measure of hospital quality that is strongly related to mortality.

A previous report on elective surgery concluded that complications and mortality are not correlated at the hospital level [3]. They argued that the focus should not be on improved operative techniques to prevent complications but on more efficient rescuing from the complications. In fact, neither our data nor the report by Haas et al. [7] replicates Ghaferi's results [3]. Trauma complication studies, including our study, recruited not only patients who underwent surgery, but also patients who underwent nonoperative management. Nonoperative management for trauma care has been increasingly mainstream every year. Most of trauma surgeries are also emergency cases. Moreover, complications of trauma are not the same as those with elective surgeries. Therefore, the management of inpatients after trauma such as pneumonia is important, even if they did not undergo surgery.

Treatments and interventions differed with hospital performance. High-mortality hospitals had more emergency procedures but fewer surgeries. Though interventions may be related to the occurrence of a complication, there have been no studies investigating this relationship. Unfortunately, we did not have data on the adequacy of any procedure. There were 


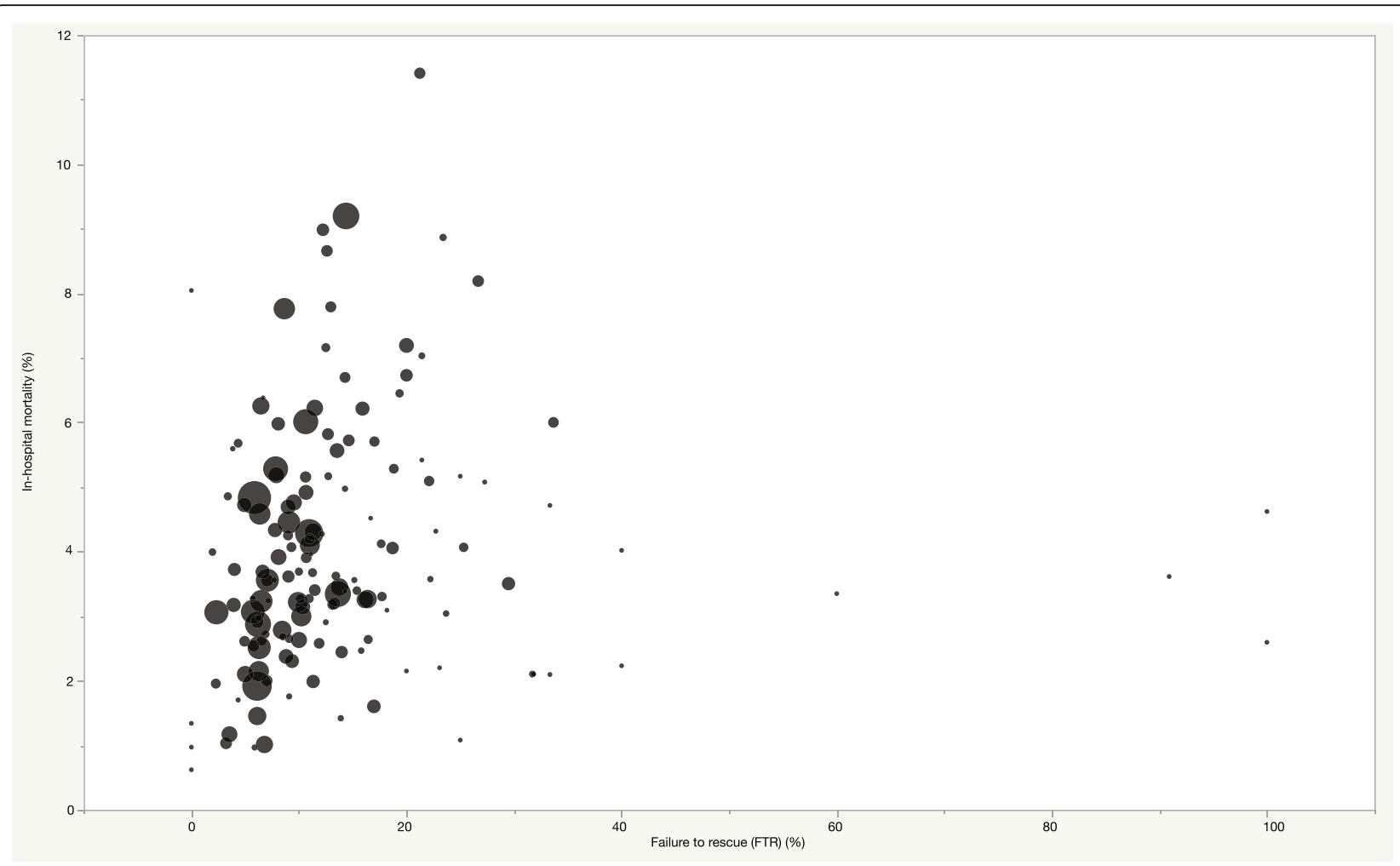

Fig. 5 Correlation between failure-to-rescue (FTR) and in-hospital mortality among patients with trauma in all hospitals ( $n=148)$. Each hospital was a bubble, whose size reflects the number of patients with any complication. Only three hospitals reported no patients with any complication. The correlation coefficient $\left(r^{2}\right)$ between FTR and in-hospital mortality was $0.0716(P=0.39)$ in all hospitals

various complications after trauma in our study, with infections and coagulopathy being the most common, but these complications did not show clinical difference according to hospital performance of trauma care. Indeed, specific complications included in studies have varied over time [14]. Though we captured trivial complications compared to other previous FTR [14], selection of complications was similar to other FTR studies in trauma patients [11]. It is plausible that not only major complications, but also trivial complications, may be related to worse outcomes.

The findings from the current and previous studies $[1,7,15]$ add to the list of growing evidence showing that management of complications is central to health outcomes. A retrospective observational study on non-trauma patients showed that low FTR hospitals had significantly more staffing resources than high FTR hospitals [4]. One study showed surgical intensivists benefited trauma patients [16]. Taken together, these findings highlight the importance of closed intensive care unit staffing (nursing, staffing, education, work environment), a higher proportion of board-certified intensivists, and inpatient support in terms of hospitalists, residents including those with teaching status, overnight care, and dedicated rapid response team in trauma practice. Though staffing and management data were not available for extraction in JTDB, these variables may have been related to reduction trauma surgery with a corresponding increase in endovascular treatment and intensive care. Others have reported that sophisticated technology and larger volumes of hospital and surgeons were modifiable hospital factors that improved FTR, although patient's factors were also related to FTR [14]. A team-based multidisciplinary approach could play an important role in trauma care by reducing judgment errors, delays in diagnosis of trauma, and crucial complications due to errors [17].

\section{Limitations}

This study is not without limitations. First, the complications lacked data on the date of occurrence and the context of each complication was unknown. However, we assessed the timing of the complications based on the type and nature of complications. Some complications like internal diseases might have caused the trauma. Second, complications may have been under-reported leading to 
underestimation or misclassification. Considering the difference in the correlation coefficient in all hospitals and specifically those that contributed to the study, it is plausible for some hospitals to have misdiagnosed or misregistered complications to JTDB. This was corroborated by the authors of a previous study who reported on the inadequate registration of complications [7]. However, another study found no meaningful differences between a registry and a chart review [18]. Thus, fair and accurate reporting of complications is essential for estimating hospital performance. Third, the impact of small hospitals is not known because we excluded hospitals that contributed little to JTDB. Fourth, we did not extract data related to treatments after complications. Fifth, we did not have the data on the type of care provided in different hospitals. We could not specify the type of care administered (unit, team, hospital characteristics, etc.) and as such could not help addressing the much needed better understanding of what made one hospital really better than another. In addition, we could not show which factors lead to better outcomes. Therefore, it might be difficult to identify what we could change at their own institution to improve outcomes. However, we know the importance of prevention of and rescue from complications.

\section{Conclusions}

Thus, complication rates and FTR are associated with in-hospital mortality rates at the center level, unlike reports of elective surgery. Better patient care in highperforming trauma hospitals could be related to a lower risk of complications and rescue from a complication.

\section{Abbreviations}

FTR: Failure-to-rescue; ISS: Injury severity score; JTDB: Japan Trauma Data Bank; ED: Emergency department; AIS: Abbreviated injury scale;

IQRs: Interquartile ranges

\section{Acknowledgements}

The authors would like to thank Enago (www.enago.jp) for the English language review. This work was supported by JSPS KAKENHI (Grant Number JP19K19376).

\section{Authors' contributions}

Concept and design: Abe, Komori, Sugiyama, Iriyama, and Kainoh Acquisition, analysis, or interpretation of data: Abe, Komori, Shiraishi, Sugiyama, and Saitoh

Drafting of the manuscript: Abe and Sugiyama

Critical revision of the manuscript for important intellectual content: all authors

Statistical analysis: Abe and Sugiyama

Administrative, technical, or material support: Abe, Shiraishi, and Saitoh Supervision: Shiraishi and Saitoh

The authors read and approved the final manuscript.

\section{Funding}

There is no financial support.
Availability of data and materials

The datasets analyzed during the current study is available with the corresponding author on reasonable request.

\section{Ethics approval and consent to participate}

The study protocol was reviewed and approved by the ethics committee of Juntendo University, Japan (IRB No.19-010). The requirement of informed consent from study participants was waived by the ethics committees because of the retrospective and anonymized nature of this study.

\section{Consent for publication}

Not applicable.

\section{Competing interests}

All authors declare that they have no competing interests.

\section{Author details}

${ }^{1}$ Department of Health Services Research, Faculty of Medicine, University of Tsukuba, 1-1-1 Tennodai, Tsukuba, Ibaraki 305-8577, Japan. ²Department of Emergency and Critical Care Medicine, Tsukuba Memorial Hospital, Tsukuba, Japan. ${ }^{3}$ Department of General Medicine, Juntendo University, Tokyo, Japan. ${ }^{4}$ Emergency and Trauma Center, Kameda Medical Center, Kamogawa, Japan. ${ }^{5}$ Diabetes and Metabolism Information Center, Research Institute, National Center for Global Health and Medicine, Tokyo, Japan. ${ }^{6}$ Department of Public Health/Health Policy, Graduate School of Medicine, The University of Tokyo, Tokyo, Japan. ${ }^{7}$ Department of Traumatology and Emergency Medicine,

National Defense Medical College, Tokorozawa, Japan.

Received: 14 November 2019 Accepted: 7 May 2020

Published online: 15 May 2020

\section{References}

1. Glance LG, Dick AW, Meredith JW, Mukamel DB. Variation in hospital complication rates and failure-to-rescue for trauma patients. Ann Surg. 2011; 253(4):811-6

2. Silber JH, Williams SV, Krakauer H, Schwartz JS. Hospital and patient characteristics associated with death after surgery. A study of adverse occurrence and failure to rescue. Med Care. 1992;30(7):615-29.

3. Ghaferi AA, Birkmeyer JD, Dimick JB. Variation in hospital mortality associated with inpatient surgery. N Engl J Med. 2009;361(14):1368-75.

4. Ward ST, Dimick JB, Zhang W, Campbell DA, Ghaferi AA. Association between hospital staffing models and failure to rescue. Ann Surg. 2019; 270(1):91-4

5. Ghaferi AA, Birkmeyer JD, Dimick JB. Complications, failure to rescue, and mortality with major inpatient surgery in Medicare patients. Ann Surg. 2009; 250(6):1029-34.

6. Sharoky CE, Martin ND, Smith BP, Pascual JL, Kaplan LJ, Reilly PM, Holena DN. The location and timing of failure-to-rescue events across a statewide trauma system. J Surg Res. 2019;235:529-35.

7. Haas B, Gomez D, Hemmila MR, Nathens AB. Prevention of complications and successful rescue of patients with serious complications: characteristics of high-performing trauma centers. J Trauma. 2011;70(3):575-82.

8. Ingraham AM, Xiong W, Hemmila MR, Shafi S, Goble S, Neal ML, Nathens $A B$. The attributable mortality and length of stay of trauma-related complications: a matched cohort study. Ann Surg. 2010;252(2):358-62.

9. Ong AW, Omert LA, Vido D, Goodman BM, Protetch J, Rodriguez A, Jeremitsky E. Characteristics and outcomes of trauma patients with ICU lengths of stay 30 days and greater: a seven-year retrospective study. Crit Care. 2009;13(5):R154.

10. Hemmila MR, Jakubus JL, Maggio PM, Wahl WL, Dimick JB, Campbell DA Jr, Taheri PA. Real money: complications and hospital costs in trauma patients. Surgery. 2008;144(2):307-16.

11. Holena DN, Kaufman EJ, Delgado MK, Wiebe DJ, Carr BG, Christie JD, Reilly PM. A metric of our own: failure to rescue after trauma. J Trauma Acute Care Surg. 2017;83(4):698-704.

12. Inoue J, Shiraishi A, Yoshiyuki A, Haruta K, Matsui H, Otomo Y. Resuscitative endovascular balloon occlusion of the aorta might be dangerous in patients with severe torso trauma: a propensity score analysis. J Trauma Acute Care Surg. 2016;80(4):559-66 discussion 566-557. 
13. Zafar SN, Shah AA, Zogg CK, Hashmi ZG, Greene WR, Haut ER, Cornwell EE 3rd, Haider AH. Morbidity or mortality? Variations in trauma centres in the rescue of older injured patients. Injury. 2016;47(5):1091-7.

14. Hatchimonji JS, Kaufman EJ, Sharoky CE, Ma L, Garcia Whitlock AE, Holena

DN. Failure to rescue in surgical patients: a review for acute care surgeons. J Trauma Acute Care Surg. 2019;87(3);699-706.

15. Almoudaris AM, Mamidanna R, Faiz O. Failure to rescue in trauma patients: operative interventions must be considered. Ann Surg. 2014;259(6):e85.

16. Nathens AB, Rivara FP, Mackenzie EJ, Maier RV, Wang J, Egleston B, Scharfstein DO, Jurkovich GJ. The impact of an intensivist-model ICU on trauma-related mortality. Ann Surg. 2006;244(4):545-54.

17. Chua WC, D'Amours SK, Sugrue M, Caldwell E, Brown K. Performance and consistency of care in admitted trauma patients: our next great opportunity in trauma care? ANZ J Surg. 2009;79(6):443-8.

18. Holena DN, Earl-Royal E, Delgado MK, Sims CA, Pascual JL, Hsu JY, Carr BG, Reilly PM, Wiebe D. Failure to rescue in trauma: coming to terms with the second term. Injury. 2016;47(1):77-82.

\section{Publisher's Note}

Springer Nature remains neutral with regard to jurisdictional claims in published maps and institutional affiliations.

Ready to submit your research? Choose BMC and benefit from:

- fast, convenient online submission

- thorough peer review by experienced researchers in your field

- rapid publication on acceptance

- support for research data, including large and complex data types

- gold Open Access which fosters wider collaboration and increased citations

- maximum visibility for your research: over $100 \mathrm{M}$ website views per year

At $\mathrm{BMC}$, research is always in progress.

Learn more biomedcentral.com/submissions 